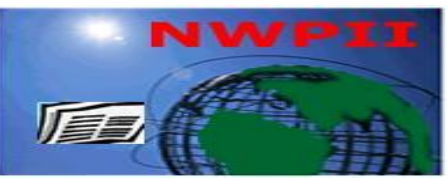

American Journal of Biomedical Sciences

ISSN: 1937-9080

nwpii.com/ajbms

\title{
Electrolyte Imbalance in Pregnant Women with Malaria Parasitaemia
}

\author{
Holy Brown, Chidinma Anthonia Azike, Uchechukwu Achor Obisike
}

Department. of Medical Laboratory Science

Rivers State University of Science and Technology

Nkpolu Oroworukwo

Port Harcourt, Nigeria

Tel: $+234-8038703710$

Email: hbinternational2002@yahoo.com and brown.holy01@ust.edu.ng

Received: 6 May 2015; | Revised: 19 June 2015; | Accepted: 8 July 2015

\begin{abstract}
Malaria in pregnancy is a life-threatening parasitic disease transmitted through the bite of female anopheles mosquitoes. Malaria is a preventable and treatable disease, yet it accounts for an estimated 660,000 deaths every year around the world mainly in Africa due to inappropriate management of imbalances in the electrolyte system of the patients. The aim of this study was to determine the severity of electrolyte imbalance in pregnant women with malaria parasitaemia. A total of 90 subject participated in the study. Sixty (60) pregnant women with malaria and thirty (30) pregnant women without malaria as control, all within the age bracket of $20-40$ years. Analysis of the mean value of $\mathrm{Na}^{+}, \mathrm{K}^{+}, \mathrm{Cl}^{-}$and $\mathrm{HCO}_{3}{ }^{-}$of the test group were significantly lower than the control $(\mathrm{P}<0.05)$. Considering the severity of electrolyte imbalance in pregnant women with malaria, it is imperative that all pregnant women with malaria parasitaemia be managed with the view of improving the electrolyte imbalance, to avert the attendant complication of electrolyte imbalance.
\end{abstract}

Keywords: Malaria, Electrolyte, Imbalance, Hypokalacemia, Hyponatraemia, and Hypocalcamia

\section{Introduction}

Malaria is a life-threatening parasitic disease transmitted through the bite of a female anopheles mosquito [1]. It is a disease that can be treated in just 48 hours, yet it can cause fetal complication if the diagnosis and treatment are delayed [2]. It affects both male and female but with higher prevalence among males and in the month of September [3, 4]. Pregnancy has been seen as a period marked by profound change in a woman's electrolyte level [5]. The ability to regulate nutrient and balance electrolyte during this period is critical to the health of the mother and the growing foetus [6]. Pregnant women and children under five years are the most vulnerable to the adverse consequences of malaria. This is so because pregnant women and children do not always receive the necessary prevention and treatments they need, and this contributes to the extremely high numbers of maternal and infant malaria related deaths. It is worst in rural areas where effective health care is farfetched. More 
so, people living in poorer locations are also more susceptible to malaria as they often live in houses that offer little protection against mosquitoes.

Anaemia on the other hand is one of the commonest resultant manifestations or complication in pregnancy arising from the leakage of potassium from intracellular space to extracellular space leading to hyperkalaemia.

In addition to water balance, these electrolytes play an important role in maintenance of $\mathrm{pH}$, regulation of heat and muscle function, electron transfer reactions as well as serving as cofactor for enzymes [7]. In pregnant women erythrocyte infected with the mature form of the malaria parasite, plasmodium falciparum, the cytosolic concentration of sodium ion is increased and that of potassium is decreased [8]. In separate studies it was observed that malaria is often associated with abnormalities of fluids, electrolyte, and acid-base balance, since electrolyte has been shown to be highly indispensable in water homeostasis which is fundamental to the survival of all organisms [2, 9]. In view of this it is imperative to assess the electrolyte status of pregnant women with malaria, its severity and provide a plat form for effective management regimen for patients in such condition.

\section{Methodology}

\subsection{Subject Selection}

The study subjects were made up of sixty (60) confirmed pregnant women with malaria recruited from the antenatal unit, $\mathrm{BMH}$ in Port Harcourt Metropolis. The subject were divided into two group based on age. The age ranges; 20 - 30 years, 30 - 40 years. Thirty apparently healthy age-match pregnant women were used as controls.

\subsection{Inclusion Criteria}

All test subjects were confirmed pregnant women with malaria.

\subsection{Exclusion Criteria}

Subjects with abnormal electrolyte imbalance were excluded from the control group of the study.

\subsection{Statistical Analysis}

Data from the study was analyzed separately using paired t-test at $95 \%$ confidence interval and analysis was done using the statistical package of social sciences (SPSS).

\subsection{Obtaining subject's personal data}

Consent was obtained from the pregnant women before the project commenced and their name, age were recorded in the questionnaire.

\subsection{Determination of Subject's Weight}

The subject was instructed to stand erect on the weighing balance and the weight reading is recorded on the questionnaires.

\subsection{Determination of the Blood Pressure}

The electronic blood pressure monitor was operated electronically, reading, the systolic and diastolic blood pressure on the screen. The subject was allowed to sit relaxed on the sit with the hand resting straight on the leg. The blood pressure pad was wrapped round the upper part of the hand and pressure was applied electronically to obtain the blood pressure which was recorded on the questionnaire.

\subsection{Sample Collection and Preparation}

The specimen bottles were used for each subject. Anticoagulant bottles containing $\mathrm{K}_{3}$ EDTA for malaria parasite test and anticoagulant bottle containing lithium heparin for electrolyte assay. The subject was allowed to sit and the tourniquet was applied with the subject's fist clenched. Blood samples were collected by clean venepuncture from the antecubital fossa using the "vacutainer" into already labeled bottles, without undue pressure to the arm. The samples were mixed by gentle inversion. The samples in the $\mathrm{K}_{3}$ EDTA anticoagulant bottle were tested for malaria parasite, after staining their thick blood films with Giemsa stain, while those sample in lithium heparin bottle were centrifuged at 3000 pm for 5 minutes to obtain the plasma. The plasma were separated into sterile plain bottles and analyzed within 4 hours. 


\subsection{Method of Determination of Malaria Parasite}

The malaria parasite density was determined by examining a thick blood film stained by Giemsa method (Randox).

\subsection{Procedure}

Immediately before use, the Giemsa stain was diluted to 1 in 10 in buffered water $\mathrm{pH}$ 7.2. The slide was face down in a staining rack for immersion in a staining trough. Thick film was thoroughly dried. This was necessary to prevent fine particles of stain being deposited on the film(s). The diluted stain was poured into the shallow tray or staining trough and stained for 30 minutes. The stain was washed from the staining container using clean water. The back of each slide was cleaned and placed in a draining rack to air dry. The slide was examined microscopically using $\mathrm{x} 40$ and $\mathrm{x} 100$ objective

\subsection{Classification of the Degree of Parasitaemia}

The malaria parasite density was graded by the semi-quantitative method recommended by the WHO plus system.

i) 1 - 10 parasite per $100 \mathrm{hpf} \quad$-------- (+) ii) $11-100$ parasite per $100 \mathrm{hpf}$ $(++)$

iii) $100-1000$ parasite per hpf $(+++)$

iv) >1000 parasite per hpf $\quad$-------- $\quad(++++)$

\subsection{Estimation of Electrolyte}

The electrolytes were measured by potentiometric process known based on the use of ion selective electrode, EasyLyte-400 (Genesis Diagnostics).

\section{Results}

The result were obtained from the research carried out on pregnant women with malaria and pregnant women without malaria at Braithwaite Memorial Specialist Hospital (BMSH) include a total of ninety (90) subjects out of these, sixty (60) were pregnant women with malarial and thirty (30) were pregnant women without malaria and were used as control. The individuals who participated in the study were between the ages of $20-40$ years. The parameters analyzed in this research work include malaria parasite, and plasma electrolyte which include sodium $\left(\mathrm{Na}^{+}\right)$, potassium $\left(\mathrm{k}^{+}\right)$, chloride $\left(\mathrm{Cl}^{-}\right)$and bicarbonate $\left(\mathrm{HCO}_{3}{ }^{-}\right)$.

Table 4.1: Comparison of Test and Control of Electrolytes using T-test

\begin{tabular}{lllll}
\hline Parameters & $\mathbf{N a}^{+}(\mathbf{m m o 1} / \mathbf{L})$ & $\mathbf{K}^{+}(\mathbf{m m o l} / \mathbf{L})$ & $\begin{array}{l}\mathbf{C L}^{-} \\
(\mathbf{m m o l} / \mathbf{L})\end{array}$ & $\begin{array}{l}\mathbf{H C O}^{-} \\
(\mathbf{m m o l} / \mathbf{L})\end{array}$ \\
\hline Test Subjects & $132.13 \pm 4.28$ & $3.76 \pm 0.34$ & $104.95 \pm 2.52$ & $15.93 \pm 1.67$ \\
Control Subjects & $138.34 \pm 4.74$ & $4.10 \pm 0.30$ & $106.3 \pm 2.82$ & $17.23 \pm 1.91$ \\
P-value & 0.0002 & 0.0002 & 0.03 & 0.002 \\
Remark & $\mathrm{S}$ & $\mathrm{S}$ & $\mathrm{S}$ & $\mathrm{S}$ \\
\hline
\end{tabular}

Table 4.2: Comparison of Test and Control of SBP and DBP using T-test

\begin{tabular}{lll}
\hline Parameters & $\begin{array}{l}\text { SBP } \\
(\mathbf{m m H g})\end{array}$ & $\begin{array}{l}\text { DBP } \\
(\mathbf{m m H g})\end{array}$ \\
\hline Test Subjects & $105.33 \pm 15.67$ & $60.83 \pm 9.79$ \\
Control subjects & $114.17 \pm 7.67$ & $70.67 \pm 7.40$ \\
P-value & 0.0005 & 0.0001 \\
Remark & $\mathrm{S}$ & $\mathrm{S}$ \\
\hline
\end{tabular}

$\mathrm{S}=$ Significant 


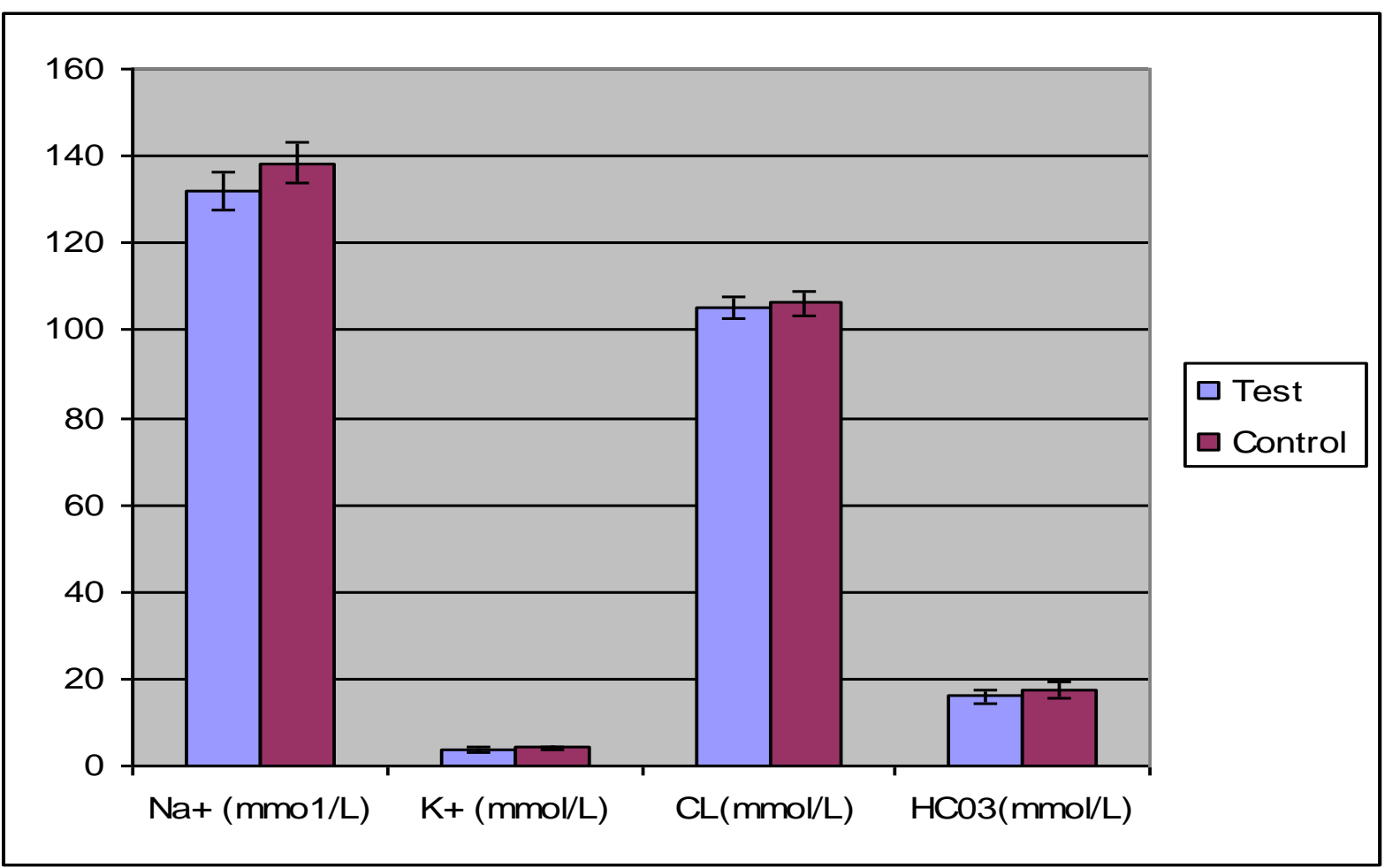

Figure 4.1 Error bars showing the mean and standard deviation of the electrolyte parameters of the test group and control.

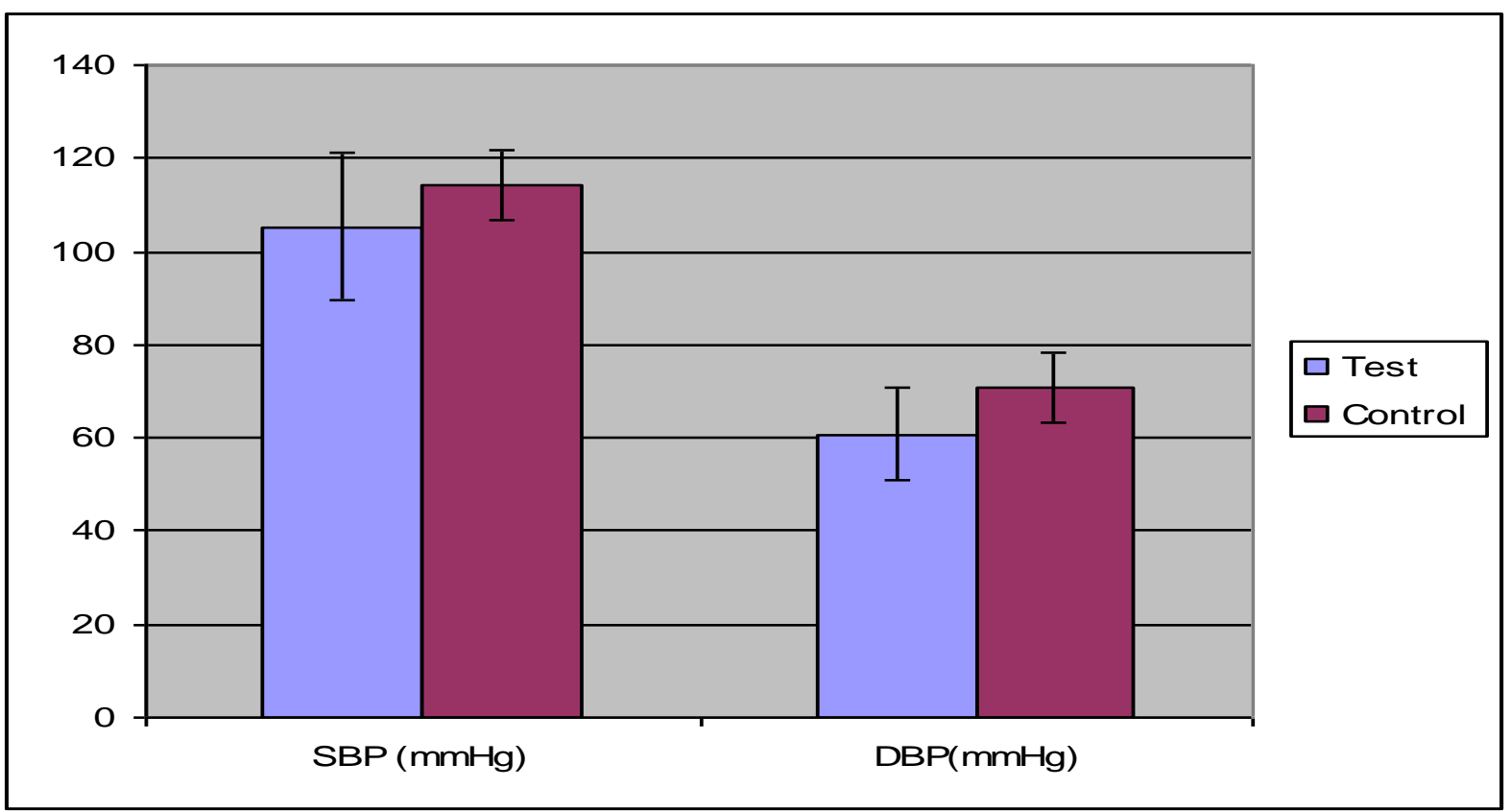

Figure 4.2 Error bar showing the mean and standard deviation of systolic blood pressure (SDP) and diastolic blood pressure (DBP) for the test group and control. 
Table 4.3: Comparison between the electrolytes, SBP and DBP of different age group of 20 - 30 years

\begin{tabular}{llllllll}
\hline $\begin{array}{l}\text { Age } \\
\text { Bracket }\end{array}$ & Parameters & $\begin{array}{l}\mathbf{S B P} \\
(\mathbf{m m H g})\end{array}$ & $\begin{array}{l}\mathbf{D B P} \\
(\mathbf{m m H g})\end{array}$ & $\begin{array}{l}\mathbf{N a}^{+} \\
(\mathbf{m m o l} / \mathbf{L})\end{array}$ & $\begin{array}{l}\mathbf{K}^{+} \\
(\mathbf{m m o l} / \mathbf{L})\end{array}$ & $\begin{array}{l}\mathbf{C L}^{-} \\
(\mathbf{m m o l} / \mathbf{L})\end{array}$ & $\begin{array}{l}\mathbf{H C O}_{3}^{-} \\
(\mathbf{m m o l} / \mathbf{L})\end{array}$ \\
\hline $20-30$ & $\begin{array}{l}\text { Test } \\
\text { Subjects }\end{array}$ & $102.65 \pm 13.1$ & $61.82 \pm 10.74$ & $132.53 \pm 4.96$ & $3.80 \pm 0.40$ & $105.85 \pm 2.69$ & $15.56 \pm 1.64$ \\
& $\begin{array}{l}\text { Control } \\
\text { Subjects }\end{array}$ & $116.92 \pm 8.55$ & $70.63 \pm 6.80$ & $137.38 \pm 2.48$ & $4.10 \pm 0.32$ & $104.69 \pm 1.84$ & $16.77 \pm 1.94$ \\
& $\begin{array}{l}\text { P - value } \\
\text { Remark }\end{array}$ & $\mathrm{S}$ & 0.0001 & 0.0005 & 0.01 & 0.10 & 0.06 \\
& $\mathrm{~S}$ & $\mathrm{~S}$ & $\mathrm{~S}$ & $\mathrm{NS}$ & $\mathrm{NS}$ \\
\hline
\end{tabular}

$\mathrm{S}=$ Significant, $\mathrm{NS}=$ Not Significant

Table 4.1 shows that there is significant decrease in the sodium of the test than that of the control $(\mathrm{P}=0.0002)$, potassium $\left(\mathrm{K}^{+}\right)$of the test and that of the control $(\mathrm{P}=0.0002)$ chloride $\left(\mathrm{Cl}^{-}\right)$ of the test and that of the control $(\mathrm{P}=0.03)$, and bicarbonate $\left(\mathrm{HCO}_{3}{ }^{-}\right)$of the test and that of the control $(\mathrm{P}=0.002)$.

Table 4.2 shows that there is a significant difference between the SBP of the test $(105.33 \pm 15.67 \mathrm{mmHg})$ and that of the control $(114.17 \pm 7.67 \mathrm{mmHg}), \mathrm{p}=0.0005$. There is also a significant difference between the DBP of the test $(60.83 \pm 9.79 \mathrm{mmHg})$ and that of the control (70.67 $\pm 7.40 \mathrm{mmHg}), \mathrm{p}=0.0001$.
Table 4.3 shows that the mean $( \pm \mathrm{SD})$ of SBP $(\mathrm{P}=0.0001)$, DBP $(\mathrm{P}=0.001), \mathrm{Na}^{+}(\mathrm{P}$ $=0.0005), \mathrm{K}^{+}(0.01)$ in age bracket $20-30$ years were significantly lower as compared to age match control while the mean $( \pm \mathrm{SD})$ of $\mathrm{Cl}^{-}(\mathrm{P}=$ $0.10)$ and $\mathrm{HCO}_{3}{ }^{-}(\mathrm{P}=0.06)$ were not significant as compared to the age match control.

Table 4.4 shows that the mean $( \pm \mathrm{SD})$ of DBP $(\mathrm{P}=0.003), \mathrm{Na}^{+}(\mathrm{P}=0.0004), \mathrm{K}^{+}(\mathrm{P}=$ $0.001)$ in age bracket $31-40$ years were significantly lower as compared to age match control and no significant difference between the mean $( \pm \mathrm{SD})$ of SBP $(\mathrm{P}=0.16)$ and $\mathrm{HCO}_{3}^{-}(\mathrm{P}=$ 0.06) as compared to age match control.

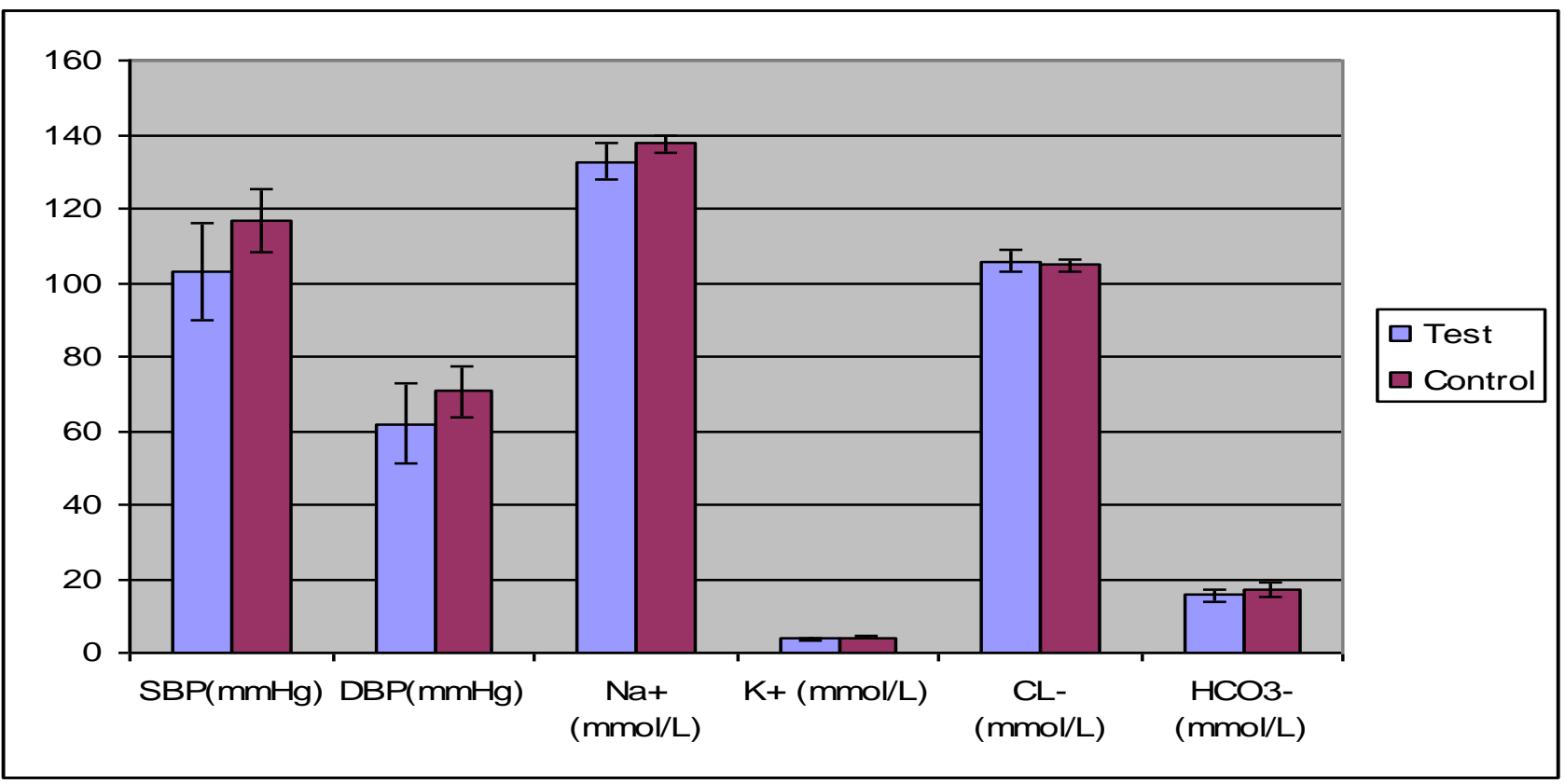

Figure 4.3 Error bar comparing the SBP,DBP and the electrolyte values of test and control group. 
Table 4.4: Comparison between the electrolytes, SBP and DBP of different age group of $31-40$ years

\begin{tabular}{llllllll}
\hline $\begin{array}{l}\text { Age } \\
\text { Bracket }\end{array}$ & Parameters & $\begin{array}{l}\text { SBP } \\
(\mathbf{m m H g})\end{array}$ & $\begin{array}{l}\mathbf{D B P} \\
(\mathbf{m m H g})\end{array}$ & $\begin{array}{l}\mathbf{N a}^{+} \\
(\mathbf{m m o l} / \mathbf{L})\end{array}$ & $\begin{array}{l}\mathbf{K}^{+} \\
(\mathbf{m m o l} / \mathbf{L})\end{array}$ & $\begin{array}{l}\mathbf{C L}^{-} \\
(\mathbf{m m o l} / \mathbf{L})\end{array}$ & $\begin{array}{l}\mathbf{H C O}_{\mathbf{3}}^{-} \\
(\mathbf{m m o l} / \mathbf{L})\end{array}$ \\
\hline $31-40$ & Test subjects & $106.8 \pm 16.76$ & $62.8 \pm 9.36$ & $131.96 \pm 3.19$ & $3.74 \pm 0.25$ & $103.84 \pm 1.7$ & $16.36 \pm 1.66$ \\
& $\begin{array}{l}\text { Control } \\
\text { subjects }\end{array}$ & $112.06 \pm 6.34$ & $71.18 \pm 7.81$ & $139.59 \pm 5.81$ & $4.06 \pm 0.31$ & $107.53 \pm 2.85$ & $17.65 \pm 1.20$ \\
& & & & & & \\
& P - value & 0.16 & 0.003 & 0.0004 & 0.001 & 0 & 0.06 \\
& Remark & $\mathrm{NS}$ & $\mathrm{S}$ & $\mathrm{S}$ & $\mathrm{S}$ & $\mathrm{S}$ & $\mathrm{NS}$ \\
\hline
\end{tabular}

$\mathrm{S}=$ Significant, $\mathrm{NS}=$ Not Significant

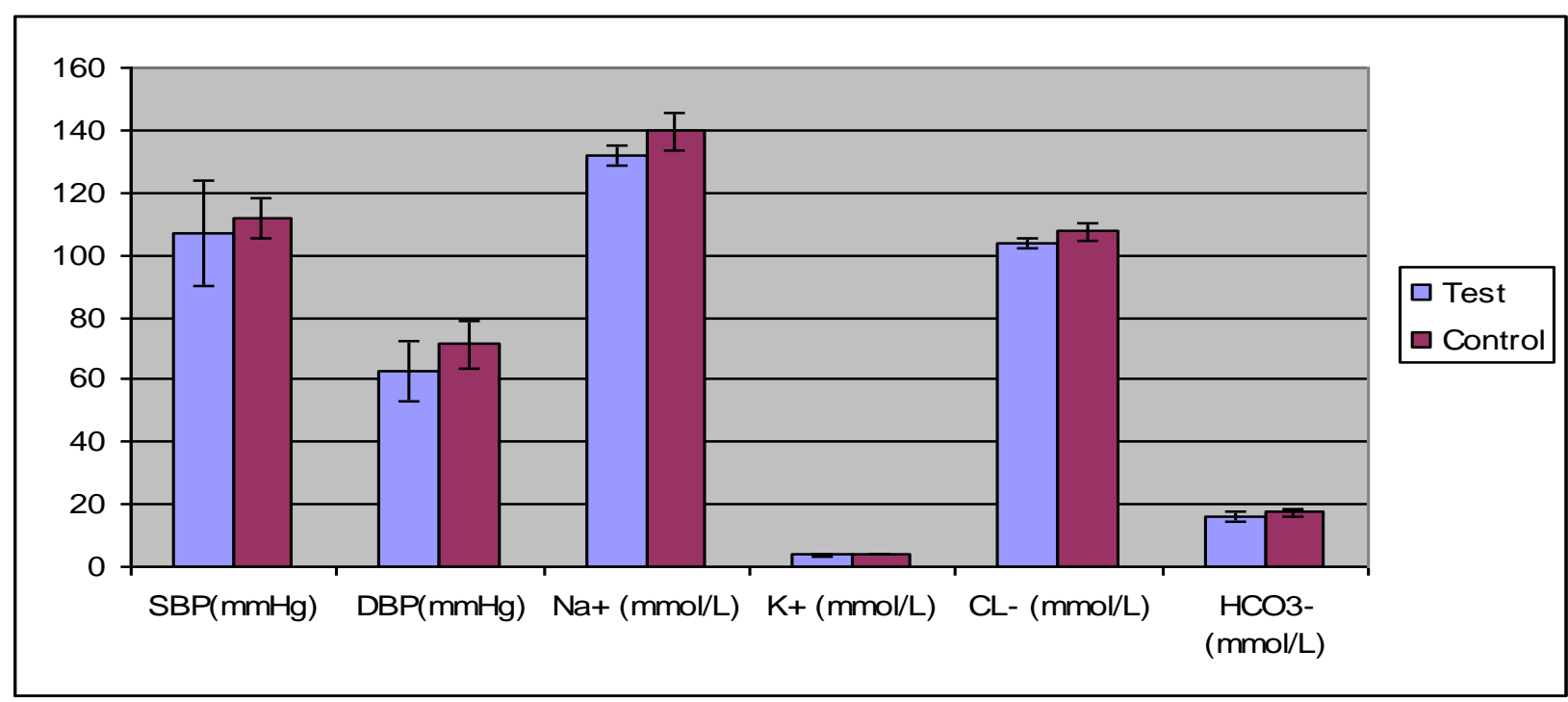

Figure 4.4 Error bar showing comparison between the electrolytes, SBP and DBP of $31-40$ years age bracket.

\section{Discussion}

The result of the study show that malaria infection leads to a reduction in the levels of serum sodium, potassium, bicarbonate and chloride. A significant difference $(\mathrm{P}<0.05)$ was observed between the pregnant women with malaria and the overall control subjects. $[10,11,12]$ stated that there is a progressive decrease in $\mathrm{Na}^{+}$and $\mathrm{K}^{+}$in 12 hours of the parasites occupancy while [2] reported a mild hyponatraemia in malaria patient. Both finding are in line with the reductions observed in the present study on these pregnant women. The reason for the decrease in $\mathrm{K}^{+}$might also be linked with the findings of [13] who reported that host cells lose up to $75-80 \%$ of their normal potassium content during the course of malaria attack. Correction of fluid volume and electrolyte deficits has been the standard of care including those with severe falciparum malaria infection. This is because acidaemia, hypokalacemia, hyponatraemia, and hypocalcamia exacerbate myocardial dysfunction and increase the risk of arrhythmias [14,15]. The decrease in concentration of sodium may be due to losses in sweat and urine. A significant decrease $(\mathrm{P}<0.05)$ was also observed in the systolic and diastolic blood pressure of these pregnant women with malaria as compared to the overall control. So while hypertension in pregnancy has been extensively studied, little attention has been paid to the other end of the spectrum, namely low blood pressure during pregnancy. [16] demonstrated that approximately 10 percent of pregnant women had a maximum 
diastolic blood pressure (DBP) of $60 \mathrm{mmhg}$ or lower. This is in line with the reduction observed in the present study on these pregnant women with malaria with a mean \pm SD of systolic blood pressure of $(105.33 \pm 15.67)$ and diastolic blood pressure of $(60.85 \pm 9.79)$ as compared to the controls which is $(114.17 \pm 7.67)$ and $(70.67 \pm$ 7.40) respectively. The study further shows the important of electrolyte management in pregnant women with malaria to prevent electrolyte depletion.

\section{Conclusion}

In conclusion, attention needs to be given to pregnant women with malaria to prevent electrolyte depletion. So serum/plasma electrolytes should be estimated in pregnant women with malaria parasitaemia to prevent complications which might result from these imbalances coupled with the effect, the malaria infection is already exerting on them as these may have grave consequences.

\section{Recommendation}

It is recommended that electrolyte estimation in pregnant women with malaria should be one aspect of antenatal care that should be given serious concern and if possible all pregnant women should be screened for malaria as part of their antenatal programme to tackle any effect if posts on their electrolyte concentration. Also antimalarial drugs should be selectively and carefully prescribed which could help to improve the treatment strategy of these pregnant women.

\section{References}

1. W.H.O. (2003). Aids to Human malaria diagnosis: Appearance of parasite stages in Giemsa-stained thin and thick blood film: WHO Division of Control of Tropical Diseases. Tropical Medicine and Hygiene, 84(3): 61-65.

2. Kakkilaya, B.S.(2003) .Malaria. Integrated Physicians Digest

3. Ahmed T,Hussain A and Ahamad S (2013). Epidemiology of malaria in Lal Qula. International Journal of Scientific and Technology Research 2(1) 2277-8618 DOI: 10.5099/aj150100009.

4. Hussain A, Ahmad T and Jamal SG(2015). Prevalence of malaria Lai Qula Pakistan, American Journal of Biomedical Science 7(1) 9-14.

5. Zavalza-Gomez, A.B., Anaya-Prado, R., and Rinan-Sanchez, A.R. (2008). Adipokines and insulin resistance during pregnancy. Diabetes Research and Clinical Practices 80:8-15 DOI: 10.4314/ijmu.v10i1.3

6. Mayne, D.P.(1994). Sodium, Potassium and Water Metabolism: in Clinical Chemistry in Diagnosis and Treatment. $6^{\text {th }}$ edition; Arnold Euston Publishers, London.pp 25-78.

7. Mattys, B., Sherkanov, T., Karimov, S.S., Mostowlanky, T., Utzinger, $\mathrm{J}$ and Wyss, K.(2008). History of malaria control in Tajikistan and rapid malaria appraisal in an Agro-ecological setting. Malaria Journal. 7:217-222 DOI: 10.1186/1475-2875-7-217.

8. Dworak, J.A., Miller, L.H., Whitehouse, W.C. and Shiroshi, T. (1975). Invasion of erythrocytes by malaria parasite. Science, 187, $748-750$.

9. Idoniji BO, Nwoke EO, Festus O and Oluba OM (2011). Plasma concentration of kidney function indicators in malaria patients in Ekpoma South- South Nigeria. International Journal of Tropical Medicine 6(1) 4-7 DOI: 10.3923/ijtmed.2011.4.7

10. Mutuku,F.M., Bayoh,M.N., Hightower,A.W., Vulele,J.M and Gimnig,J.E.(2009). A supervised land cover classification of Western Kenya lowland Endemic for human malaria: Association of land cover with 
larval anopheles habitat. International Journal of Health Geography, 8:9-19. DOI: $\underline{10.1186 / 1476-072 X-8-19}$

11. Cheesebrough M.(2006). Examination of blood for malaria parasites. Medical Laboratory Manual: $2^{\text {nd }}$ edition update; Cambridge University press, New York.

12. Elbadawi NE,IbrahimEK, Ismeal M,Ahmad EGE, Adan AO and Ogail YD(2013). Effect of malaria on biochemical renal function in Sudanese pregnant women. Journal of Cell Biology and Biochemistry Research (1) 4-7.

13. Heindricks, R.G, Hassan AH, Olurinde LO, and Akindkani A.(1971). Malaria in early childhood. Annals of Tropical Medicine. 65,316-320

14. Seal SL, Mukhopahay S and Ganguly RP (2010). Malaria in pregnancy. Journal of Indian Medical Association 108(8) 487-490.

15. Khilnami, P. (1992). Electrolyte abnormality in critically ill children. Journal of Critical Care Medicine, 20, 241-250.

16. Friedman EA and Neff RK. (2002). Pregnancy, outcome as related to hypertension, edema, and proteinuria. Perspect Nephrol Hypertens 261, 243-253. 